\title{
Influence of Composition and Processing Parameters on the Properties of Solution-Processed Aluminum Phosphate Oxide (AIPO) Thin Films
}

Kevin M. Norelli, ${ }^{\dagger}$ Paul N. Plassmeyer ${ }^{\dagger}{ }^{\dagger}$ Keenan N. Woods, ${ }^{\dagger}$ Benjamin A. Glassy, ${ }^{\dagger}$ Christopher C. Knutson, Matt Beekman, ${ }^{\S}$ and Catherine J. Page ${ }^{t^{*}}$

${ }^{\dagger}$ Department of Chemistry, University of Oregon, 1253 University of Oregon, Eugene, OR 97403, United States

Department of Chemistry, Oregon State University, 153 Gilbert Hall, Corvallis, OR 97331, United States

${ }^{\S}$ Department of Natural Sciences, Oregon Institute of Technology, Klamath Falls, OR 97601, United States

\begin{abstract}
The effects of precursor solution concentration, composition, and spin-processing parameters on the thickness and electrical properties of ultra-smooth aluminum oxide phosphate $\left(\mathrm{Al}_{2} \mathrm{O}_{3}\right.$ ${ }_{3 x}\left(\mathrm{PO}_{4}\right)_{2 x}$ or "AIPO") thin films prepared using aqueous solutions are reported. Compositions were verified by electron probe micro-analysis and range from $\mathrm{Al}_{2} \mathrm{O}_{1.5}\left(\mathrm{PO}_{4}\right)$ to $\mathrm{AlPO}_{4}(\mathrm{X}=\mathrm{P}: \mathrm{Al}$ from $0.5-1.0)$. Film thicknesses were determined using $X$-ray reflectivity measurements and were found to depend systematically on solution concentration, P:Al ratio, and spin-speed. Metal-insulator-semiconductor devices were fabricated to determine electrical properties as a function of composition. As the P:Al ratio increased from 0.5 to 1.0, the dielectric constant decreased from 6.0 to 4.6 , leakage currents increased from 0.45 to $65 \mathrm{nA} \mathrm{cm} \mathrm{cm}^{-2}$ at $1 \mathrm{MV} \mathrm{cm}^{-1}$ and dielectric breakdown (defined as leakage currents $>10 \mu \mathrm{A} \mathrm{cm}^{-2}$ ) decreased from 9.74 to 2.84 $\mathrm{MV} \mathrm{cm}^{-1}$. These results establish composition, concentration, and spin-speed for the production of AIPO films with targeted thicknesses and electrical properties.
\end{abstract}

Keywords: amorphous, aqueous, dielectrics, solution-processed, thin films, aluminum phosphate 


\section{Introduction}

Metal oxide thin films are essential components in a variety of electronic device structures, including dielectric and channel layers in thin-film transistors (TFTs) ${ }^{1}$ and metaloxide-semiconductor field effect transistors (MOSFETs), ${ }^{2}$ charge trapping layers for memory devices, ${ }^{3}$ and as passivation or catalyst layers for photovoltaics. ${ }^{4,5}$ In most of these applications the film morphology, composition, and the electrical properties are critical to the performance of the devices.

In principle, a thin film of a given chemical composition should have a well-defined set of properties. To a first approximation this is true, but many secondary factors impact thin film chemical and physical properties and device performance. These include the concentration and nature of defects and impurities, ${ }^{6}$ the extent or lack of crystallinity, crystallite size and orientation, ${ }^{1,7}$ overall thickness, morphology, and porosity. In general, these secondary factors are strongly influenced by the synthetic route and processing parameters used to fabricate a particular film.

The techniques for fabricating metal oxide thin films can be broadly divided into either vapor-phase or solution-phase deposition. In general, the vapor-phase deposition techniques tend to yield films of higher quality ${ }^{8}$ and, in some cases, these films can be made to conform to complex substrate architectures. ${ }^{9}$ However, vapor-phase routes often require reactive precursors $^{10,11}$ and specialized deposition equipment, resulting in high cost and low atom economy due to wasted reactants. By contrast, solution-phase deposition techniques are relatively inexpensive, require relatively simple deposition equipment, and allow for reduced waste.

Most solution-deposited metal oxide thin films are produced using the sol-gel route, which employs metal alkoxides or other precursors with organic ligands. ${ }^{12,13}$ The sol is deposited onto a substrate, typically via spin- or dip-coating, and thermally processed to remove organics and promote condensation to the desired metal-oxide. Because of the high volume fraction of organic ligands and solvent which must be expelled during processing, the resulting films often suffer from relatively low density, high porosity, and unwanted electronic defects. ${ }^{14}$

A related paradigm, "prompt inorganic condensation" or PIC, ${ }^{15-21}$ has been developed using aqueous solutions of metal inorganic salts. PIC minimizes the number and size of counterions in thin film precursor solutions while simultaneously forming solubilized polynuclear metal-oxo or -hydroxo species. Prompt heating of spin-cast solutions enables a 
relatively smooth transition to thin film metal oxides. ${ }^{22} \mathrm{PIC}$ has been used to make a variety of amorphous semiconducting and insulating metal oxide (as well as metal sulfate and metal phosphate) thin films, including aluminum phosphate oxide films. ${ }^{15,19,21,23}$ Generally, this technique produces films which meet or surpass the quality of sol-gel derived films and frequently rival that of vapor-deposited films. ${ }^{15,22,24-27}$

Aluminum phosphate oxide $\left(\mathrm{Al}_{2} \mathrm{O}_{3-3 x}\left(\mathrm{PO}_{4}\right)_{2 x}\right.$ or "AIPO") is of interest as a catalyst for the conversion of methanol to dimethyl ether, ${ }^{28}$ as a cathode coating material for lithium-ion batteries, ${ }^{29}$ and as a dielectric component for thin-film devices. ${ }^{15,19,30}$ Previously, vapor phase methods (atomic layer epitaxy (ALE) ${ }^{31}$ and atomic layer deposition (ALD) ${ }^{32,33}$ ) have been used to prepare AIPO films. Solution-phase PIC has also been employed to prepare amorphous AIPO films with dielectric properties comparable to thermally grown $\mathrm{SiO}_{2}{ }^{15,19,21,23}$ These AIPO films have been successfully employed as gate dielectrics in high-performing thin-film transistor (TFT) devices that are competitive with a-Si TFTs. ${ }^{24}$ For the latter application, incorporation of phosphate into an aluminum oxide matrix suppresses crystallization, yielding desirable amorphous films over a range of firing temperatures (up to $600^{\circ} \mathrm{C}$ in the current study). Additionally, the simple PIC solution preparation allows for facile manipulation of the $\mathrm{P}: \mathrm{Al}$ ratio $(\mathrm{x})$ and of the resulting thin film properties.

In this contribution, we examine the impact of the precursor solution concentration, $\mathrm{P}: A \mathrm{l}$ ratio, and spin-speed on the thickness and electrical properties of resultant amorphous AIPO thin films. We show that film thickness is approximately linearly dependent on solution concentration. This relationship, while not unexpected, has not been explicitly shown previously for PIC-produced films. In addition, the stoichiometry of P:Al in the films is shown to closely match that of the precursor solutions, enabling precise control of film composition. The studies reported here allow the production of AIPO films with specified thicknesses and electrical characteristics based on simple manipulation of concentration, $\mathrm{P}: \mathrm{Al}$ ratio and spin processing parameters.

\section{Experimental Section}

Materials. $\mathrm{Al}(\mathrm{OH})_{3} \cdot \mathrm{xH}_{2} \mathrm{O}$ (Alfa Aesar, $76.5 \%$ ) was standardized through thermal conversion to the oxide $\left(\mathrm{Al}_{2} \mathrm{O}_{3}\right)$ in a tube furnace in air and gravimetric analysis to determine the degree of hydration for accurate mass calculations. Trace metal grade $\mathrm{HNO}_{3}$ (Fisher, $70 \% \mathrm{w} / \mathrm{w}$ ) and $\mathrm{H}_{3} \mathrm{PO}_{4}$ (EMD Chemicals, $85 \% \mathrm{w} / \mathrm{w}$ ) were used as received. 
Solution Synthesis. $1.00 \mathrm{M} \mathrm{Al}^{3+}$ precursor solutions of various $\mathrm{P}: \mathrm{Al}$ ratio were made by adding two equivalents of nitric acid drop-wise to a suspension of $\mathrm{Al}(\mathrm{OH})_{3}$ in $18 \mathrm{M} \Omega$ water and heated to $95^{\circ} \mathrm{C}$. The solution was stirred overnight to achieve complete dissolution. The appropriate amount of phosphoric acid was added drop-wise, followed by dilution to the final volume. The stock solution was then diluted to achieve the desired precursor solution concentrations reported below.

Film Preparation and Characterization. Polished, conductive n-type silicon substrates (100) supplied by SumCo-Oregon were exposed to an oxygen plasma in a March CS-1701 generated by a $150 \mathrm{~W}$ RF field for $120 \mathrm{~s}$ at $300 \mathrm{mTorr}$ and $74.6 \mathrm{sccm}$ of pure $\mathrm{O}_{2}$. The oxygen plasma treatment generates a hydrophilic $\mathrm{SiO}_{2}$ layer which promotes solution adhesion and uniform wetting.

AIPO films were produced by coating a freshly plasma-treated silicon substrate with precursor solution deposited using a syringe fitted with a $0.45 \mu \mathrm{m}$ PTFE filter. The coated substrate was spun at the desired rate (2000 to 5000 RPM) for $30 \mathrm{~s}$, immediately transferred to a pre-heated hotplate at $300{ }^{\circ} \mathrm{C}$ for $60 \mathrm{~s}$, and subsequently annealed in a box furnace at $600{ }^{\circ} \mathrm{C}$ for $10 \mathrm{~min}$.

Film thicknesses were determined by X-ray reflectivity (XRR) measurements on a Bruker D8 Discover diffractometer with a Cu-Ka radiation source $\left(\lambda_{\text {avg }}=1.5418 \AA\right)$. Reflectivity data were analyzed using the EVA software package to locate Kiessig fringe positions and a modified form of Bragg's Law (corrected for refraction). Because AIPO and $\mathrm{SiO}_{2}$ have similar electron densities, thicknesses determined by XRR include contributions from both the AIPO film and the underlying $\mathrm{SiO}_{2}$ layer. Ellipsometry measurements to determine native $\mathrm{SiO}_{2}$ thicknesses were conducted using a J. A. Woollam Co., Inc. EC-270 Spectroscopic Ellipsometer equipped with a LPS-400 75W Xenon Light Source. The AIPO film thicknesses reported in the Results section have been corrected for the $\mathrm{SiO}_{2}$ thickness and reflect the thickness of only the AIPO layer. X-ray diffraction experiments were also performed on the Bruker D8 Discover diffractometer to qualitatively evaluate the crystalline or amorphous nature of the films.

FT-IR experiments were performed on a Nicolet Magna 560 spectrometer using a spectrum collected from a bare, plasma treated silicon substrate as the background. Electron probe micro-analysis (EPMA) was performed on films deposited from $1.00 \mathrm{M} \mathrm{Al}^{3+}$ solutions with a Cameca SX-50, referencing alumina and apatite as elemental standards. The resultant raw X-ray intensities were corrected as outlined by Donovan and Tingle. ${ }^{34}$ Electron 
micrographs were obtained using a Zeiss Ultra-55 FESEM with a $20 \mu \mathrm{m}$ aperture and $5 \mathrm{kV}$ accelerating voltage.

Electrical Characterization. Metal-insulator-semiconductor (MIS) devices were prepared by depositing AIPO films onto degenerately-doped silicon substrates and thermally depositing aluminum top contacts ( $100 \mathrm{~nm}$ thick, $1.10 \mathrm{~mm}^{2}$ dots) using an Edwards E306A Coating System. Contact to the underlying degenerately doped silicon was achieved by scratching through the insulating layers and applying indium-gallium eutectic. All MIS devices used films which had been annealed at $600{ }^{\circ} \mathrm{C}$ for 30 minutes, and resulting thicknesses ranged from 78 to $100 \mathrm{~nm}$.

Capacitance and loss tangent measurements on films deposited from $1.00 \mathrm{M} \mathrm{Al}^{3+}$ solutions were made using an HP Agilent 4284A LCR connected to a two-point probe station. All capacitance measurements were performed at $50 \mathrm{mV} \mathrm{AC}$ oscillating at $10 \mathrm{kHz}$ with $0 \mathrm{~V}$ DC bias. Breakdown measurements were made using a Hewlett-Packard 4140B picoammeter with a $1 \mathrm{~V} \mathrm{~s}^{-1}$ ramp. Breakdown is herein defined as the applied field strength at which the leakage current density meets or exceeds $10 \mu \mathrm{A} \mathrm{cm}^{-2}$.

For comparison, a standard device was fabricated using a $100 \mathrm{~nm}$ thermally grown silicon oxide on degenerately-doped $\mathrm{p}^{+}$silicon (resistivity $<1 \Omega \mathrm{cm}^{-1}$ ) with a chromium gold back (supplied by Hewlett Packard, Corvallis). Aluminum top contacts were thermally deposited on the silicon oxide sample by the procedure outlined above.

\section{Results and Discussion}

The physical and electrical properties of thin films derived from aqueous solutions are sensitive to annealing conditions. Annealing temperatures must be sufficiently high to ensure complete water and counterion removal with a high degree of condensation but low enough to prevent crystallization (in cases where amorphous films are desired). IR spectroscopy was used to qualitatively probe residual water and nitrate content in films annealed at various temperatures, and the IR spectra indicate that removal of water and nitrate is complete by $600{ }^{\circ} \mathrm{C}$ (SD Fig. 1). Therefore, $600^{\circ} \mathrm{C}$ was chosen as the annealing temperature for the remainder of the thin film characterization studies.

Although it has been previously reported that AIPO films prepared via PIC with relatively high $\mathrm{P}: \mathrm{Al}(\mathrm{x} \geq 0.8)$ tend to crystallize at relatively low annealing temperatures $\left(<275^{\circ} \mathrm{C}\right),{ }^{15} \mathrm{XRD}$ of the AlPO compositions from $\mathrm{x}=0.5$ to 1.0 studied herein showed no 
evidence of crystallization at annealing temperatures up to $600^{\circ} \mathrm{C}$. This difference may be the result of slightly different precursor formulations. We used $\mathrm{HNO}_{3}$ instead of $\mathrm{HCl}$ for the dissolution of $\mathrm{Al}(\mathrm{OH})_{3}$ in the precursor solutions because, in our experience, precursor solutions prepared with $\mathrm{HNO}_{3}$ generally wet the $\mathrm{Si}$ substrate better, resulting in smoother films with fewer surface defects. The observation that nitrate-containing films do not crystallize readily, in addition to our prior observation that nitrate solutions produce films with better morphology, suggest that counterion identity may play an important role in film formation.

EPMA results show that the P:Al ratios of the films closely match those of the corresponding precursor solutions, indicating that the film composition can be accurately controlled by precursor stoichiometry (Table 1).

Table 1. Electron probe micro-analysis results of $\mathrm{Al}_{2} \mathrm{O}_{3-3 x}\left(\mathrm{PO}_{4}\right)_{2 x}$. Error in $\mathrm{x}$ values are estimated to be \pm 0.01 .

Thin film thicknesses were determined using XRR. Although a detailed analysis of roughness is outside the scope of this study, the presence of Kiessig fringes extending out to relatively high $2 \theta\left(\sim 8^{\circ}\right)$ indicates that the average roughness of the films is $<1 \mathrm{~nm}$ (SD Fig. 2), consistent with that observed for other PIC-deposited films. ${ }^{15,16}$ Film thickness increases approximately linearly with solution concentration for a given P:Al ratio (Fig. 1, SD Fig. 3). The observed increase in thickness with increasing P:Al ratio is attributable to higher total precursor concentration $\left(\left[\mathrm{Al}^{3+}\right]+\left[\mathrm{PO}_{4}{ }^{3-}\right]\right)$. Viscosity changes with concentration may account for deviations from linearity.

Figure 1. AIPO film thickness as a function of $\left[A l^{3+}\right]$ for a series of $P: A l$ ratios, $x$ (left). Results from linear regressions of film thickness as a function of solution concentration are tabulated (right) and fits are shown in SD Fig. 3.

Spin-speed during the spin-coating process also impacts film thickness (Fig. 2). Film thickness shows an inverse square root dependence on spin-speed, which has also been observed for a variety of spin-processed organic polymer thin films. ${ }^{39,40}$

Figure 2. Thicknesses of films with $0.50 \mathrm{M} \mathrm{Al}^{3+}$ and variable $\mathrm{P}$ :Al ratio as a function of spin-speed (solid line represents an ideal inverse square root dependence). 
Current-voltage (leakage current) and capacitance measurements were performed on MIS capacitors in which AIPO layers of varying P:Al (prepared from $1.00 \mathrm{M}$ solutions and annealed at $600^{\circ} \mathrm{C}$ ) were employed as the insulating dielectric. Dielectric constants (K), losstangents, and leakage currents show a tendency to increase with increasing P:Al ratio (Table 2, Fig. 3). Loss tangents in all films are below $2 \%$ and therefore indicate reasonable dielectric performance. The relative dielectric constant is demonstrated to increase as P:Al ratio increases, thereby demonstrating that this property can be tuned by careful stoichiometric control of precursor solutions. The breakdown field increases with decreasing P:Al, and the lowest loss tangent is observed for the lowest phosphate composition studied $(x=0.5)$. Since the breakdown voltage and dielectric constant trend in opposite directions with respect to $\mathrm{x}$, the electrical properties can be tuned for a specific application by choosing the appropriate $P: A l$ ratio.

Table 2. Capacitance measurements made on MIS devices.

Figure 3. Leakage current density and dielectric breakdown for a range of AIPO films.

\section{Conclusions}

We have shown that composition, thickness, and electrical properties of AIPO thin films can be finely tuned by controlling precursor solution concentration, composition, and spin-processing parameters. EPMA demonstrates that precursor solution stoichiometry is retained in the resulting thin films. Reflectivity data indicate an approximately linear relationship between film thickness and precursor concentration in the concentration range examined. The inverse square root dependence of film thickness on spin-speed follows a trend commonly observed in a variety of spin-cast organic polymer films. The electrical characteristics of thin films processed using identical conditions were found to depend upon the $\mathrm{P}: \mathrm{Al}$ ratio. Although films with higher $\mathrm{P}: \mathrm{Al}$ tend to have higher dielectric constants they also tend to have larger leakage current densities and loss-tangents.

This work provides a useful guide for tailoring the chemical, physical, and device characteristics of AIPO dielectric thin films via the manipulation of solution concentration, stoichiometry, and spin-processing parameters. In addition, the observed trends in film 
thickness as a function of concentration and spin parameters observed in this AIPO study should be general for other aqueous PIC systems.

\section{Author Information}

Corresponding Author

*E-mail: cpage@uoregon.edu; Phone: (541) 346-4693

Author Contributions

This manuscript was written through contributions of all authors. All authors have given approval to the final version of the manuscript.

\section{Acknowledgements}

The authors would like to thank Phillip Mudder, Garrett Cogburn, and Lauren Irinaga for their initial experimental work as a part of the NSF Summer Program in Solid State Chemistry (DMR-1105438) and the UCORE Program (DUE-0622620). We also thank Douglas Keszler and David Johnson for helpful discussions. This work was supported by the National Science Foundation Center for Sustainable Materials Chemistry, NSF grant CHE-1102637.

\section{References}

(1) Fortunato, E.; Barquinha, P.; Martins, R. Oxide Semiconductor Thin-Film Transistors: A Review of Recent Advances. Adv. Mater. 2012, 24, 2945-2986.

(2) Robertson, J. High Dielectric Constant Gate Oxides for Metal Oxide Si Transistors. Reports Prog. Phys. 2006, 69, 327-396.

(3) Kobayashi, D.; Shibata, T.; Fujimori, Y.; Nakamura, T.; Takasu, H. A Ferroelectric Associative Memory Technology Employing Heterogate FGMOS Structure. IEEE Trans. Electron Devices 2005, 52, 2188-2197.

(4) Spinelli, P.; Macco, B.; Verschuuren, M. A.; Kessels, W. M. M.; Polman, A. Al2O3/TiO2 Nano-Pattern Antireflection Coating with Ultralow Surface Recombination. Appl. Phys. Lett. 2013, 102, 233902.

(5) Trotochaud, L.; Boettcher, S. W. Precise Oxygen Evolution Catalysts: Status and Opportunities. Scr. Mater. 2014, 74, 25-32. 
(6) Ganduglia-Pirovano, M. V.; Hofmann, A.; Sauer, J. Oxygen Vacancies in Transition Metal and Rare Earth Oxides: Current State of Understanding and Remaining Challenges. Surf. Sci. Rep. 2007, 62, 219-270.

(7) Park, J. S.; Maeng, W.-J.; Kim, H.-S.; Park, J.-S. Review of Recent Developments in Amorphous Oxide Semiconductor Thin-Film Transistor Devices. Thin Solid Films 2012, $520,1679-1693$.

(8) Leskelä, M.; Ritala, M. Atomic Layer Deposition (ALD): From Precursors to Thin Film Structures. Thin Solid Films 2002, 409, 138-146.

(9) Knez, M.; Nielsch, K.; Niinistö, L. Synthesis and Surface Engineering of Complex Nanostructures by Atomic Layer Deposition. Adv. Mater. 2007, 19, 3425-3438.

(10) Bernal Ramos, K.; Saly, M. J.; Chabal, Y. J. Precursor Design and Reaction Mechanisms for the Atomic Layer Deposition of Metal Films. Coord. Chem. Rev. 2013, 257, 3271-3281.

(11) Pierson, H. O. Handbook of Chemical Vapor Deposition: Principles, Technology and Applications; 2nd Ed.; William Andrew Publishing: Norwich, 1999.

(12) Bhuiyan, M. S.; Paranthaman, M.; Salama, K. Solution-Derived Textured Oxide Thin Films-a Review. Supercond. Sci. Technol. 2006, 19, R1-R21.

(13) Jia, Q. X.; McCleskey, T. M.; Burrell, A. K.; Lin, Y.; Collis, G. E.; Wang, H.; Li, A. D. Q.; Foltyn, S. R. Polymer-Assisted Deposition of Metal-Oxide Films. Nat. Mater. 2004, 3, 529-532.

(14) Wang, Z.; Helmersson, U.; Käll, P.-O. Optical Properties of Anatase TiO2 Thin Films Prepared by Aqueous Sol-gel Process at Low Temperature. Thin Solid Films 2002, $405,50-54$.

(15) Meyers, S. T.; Anderson, J. T.; Hong, D.; Hung, C. M.; Wager, J. F.; Keszler, D. A. Solution-Processed Aluminum Oxide Phosphate Thin-Film Dielectrics. Chem. Mater. 2007, 19, 4023-4029.

(16) Anderson, J. T.; Munsee, C. L.; Hung, C. M.; Phung, T. M.; Herman, G. S.; Johnson, D. C.; Wager, J. F.; Keszler, D. A. Solution-Processed HafSOx and ZircSOx Inorganic Thin-Film Dielectrics and Nanolaminates. Adv. Funct. Mater. 2007, 17, 2117-2124. 
(17) Meyers, S. T.; Anderson, J. T.; Hung, C. M.; Thompson, J.; Wager, J. F.; Keszler, D. A. Aqueous Inorganic Inks for Low-Temperature Fabrication of ZnO TFTs. J. Am. Chem. Soc. 2008, 130, 17603-17609.

(18) Jiang, K.; Zakutayev, A.; Stowers, J.; Anderson, M. D.; Tate, J.; McIntyre, D. H.; Johnson, D. C.; Keszler, D. A. Low-Temperature, Solution Processing of TiO2 Thin Films and Fabrication of Multilayer Dielectric Optical Elements. Solid State Sci. 2009, 11, 1692-1699.

(19) Alemayehu, M.; Davis, J. E.; Jackson, M.; Lessig, B.; Smith, L.; Sumega, J. D.; Knutson, C.; Beekman, M.; Johnson, D. C.; Keszler, D. A. Tunable Dielectric Thin Films by Aqueous, Inorganic Solution-Based Processing. Solid State Sci. 2011, 13, 20372040.

(20) Jiang, K.; Anderson, J. T.; Hoshino, K.; Li, D.; Wager, J. F.; Keszler, D. A. Low-Energy Path to Dense HfO2 Thin Films with Aqueous Precursor. Chem. Mater. 2011, 23, 945952.

(21) Jiang, K.; Meyers, S. T.; Anderson, M. D.; Johnson, D. C.; Keszler, D. A. Functional Ultrathin Films and Nanolaminates from Aqueous Solutions. Chem. Mater. 2013, 25, 210-214.

(22) Keszler, D. A.; Anderson, J. T.; Meyers, S. T. In Solution Processing of Inorganic Materials; Mitzi, D. B., Ed.; John Wiley \& Sons, Inc.: Hoboken, NJ, USA, 2008; pp. 109-129.

(23) Anderson, J. T.; Wang, W.; Jiang, K.; Gustafsson, T.; Xu, C.; Gafunkel, E. L.; Keszler, D. A. Chemically Amplified Dehydration of Thin Oxide Films. ACS Sustain. Chem. Eng. 2015, 3, 1081-1085.

(24) Kim, K. M.; Kim, C. W.; Heo, J. S.; Na, H.; Lee, J. E.; Park, C. B.; Bae, J.-U.; Kim, C.D.; Jun, M.; Hwang, Y. K.; Meyers, S. T.; Grenville, A.; Keszler, D. A. Competitive Device Performance of Low-Temperature and All-Solution- Processed Metal-Oxide Thin-Film Transistors. Appl. Phys. Lett. 2011, 99, 242109.

(25) Smith, S. W.; Wang, W.; Keszler, D. A.; Conley, J. F. Solution Based Prompt Inorganic Condensation and Atomic Layer Deposition of Al2O3 Films: A Side-by-Side Comparison. J. Vac. Sci. Technol. A Vacuum, Surfaces, Film. 2014, 32, 041501.

(26) Plassmeyer, P. N.; Archila, K.; Wager, J. F.; Page, C. J. Lanthanum Aluminum Oxide Thin-Film Dielectrics from Aqueous Solution. ACS Appl. Mater. Interfaces 2015, 7, 1678-1684. 
(27) Nadarajah, A.; Wu, M. Z. B.; Archila, K.; Kast, M. G.; Smith, A. M.; Chiang, T. H.; Keszler, D. A.; Wager, J. F.; Boettcher, S. W. Amorphous In-Ga-Zn Oxide Semiconducting Thin Films with High Mobility from Electrochemically Generated Aqueous Nanocluster Inks. Chem. Mater. 2015, 27, 5587-5596.

(28) Yaripour, F.; Mollavali, M.; Jam, S. M.; Atashi, H. Catalytic Dehydration of Methanol to Dimethyl Ether Catalyzed by Aluminum Phosphate Catalysts. Energy \& Fuels 2009, 23, 1896-1900.

(29) Cho, J.; Kim, Y.-W.; Kim, B.; Lee, J.-G.; Park, B. A Breakthrough in the Safety of Lithium Secondary Batteries by Coating the Cathode Material with AIPO4 Nanoparticles. Angew. Chemie Int. Ed. 2003, 42, 1618-1621.

(30) Daviero, S.; Avinens, C.; Ibanez, A.; Giuntini, J. C.; Philippot, E. Dielectric Properties of Amorphous Aluminium Phosphate Thin Films. J. Non. Cryst. Solids 1992, 146, 279284.

(31) Tiitta, M.; Nykanen, E.; Soininen, P.; Niinisto, L.; Leskela, M.; Lappalainen, R. Preparation and Characterization of Phosphorus-Doped Aluminum Oxide Thin Films. Mater. Res. Bull. 1998, 33, 1315-1323.

(32) Hämäläinen, J.; Holopainen, J.; Munnik, F.; Heikkilä, M.; Ritala, M.; Leskelä, M. Atomic Layer Deposition of Aluminum and Titanium Phosphates. J. Phys. Chem. C 2012, 116, 5920-5925.

(33) Liu, J.; Tang, Y.; Xiao, B.; Sham, T.-K.; Li, R.; Sun, X. Atomic Layer Deposited Aluminium Phosphate Thin Films on N-Doped CNTs. RSC Adv. 2013, 3, 4492-4495.

(34) John, J. J.; Tingle, T. N. An Improved Mean Atomic Number Background Correction for Quantitative Microanalysis. J. Microsc. Soc. Am. 1996, 2, 1-7.

(35) Sukanek, P. C. Dependence of Film Thickness on Speed in Spin Coating. J. Electrochem. Soc. 1991, 138, 1712-1719.

(36) Yonkoski, R. K.; Soane, D. S. Model for Spin Coating in Microelectronic Applications. J. Appl. Phys. 1992, 72, 725-740. 


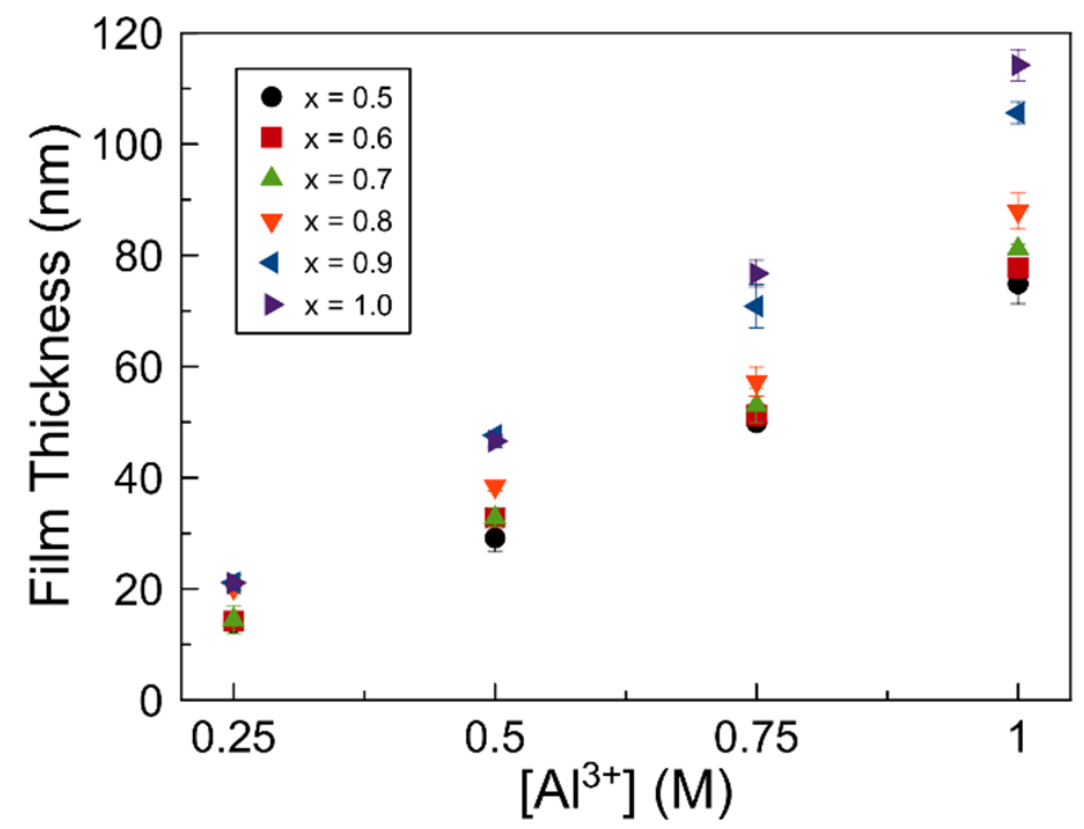

\begin{tabular}{|c|c|}
\hline $\begin{array}{c}\text { Targeted } x \\
\text { Value }\end{array}$ & $\begin{array}{c}\text { Slope } \\
\left(\mathrm{nm} \mathrm{M}^{-1}\right)\end{array}$ \\
\hline 0.50 & 70 \\
\hline 0.60 & 73 \\
\hline 0.70 & 75 \\
\hline 0.80 & 83 \\
\hline 0.90 & 100 \\
\hline 1.00 & 107 \\
\hline
\end{tabular}

$\left[\mathrm{Al}^{3+}\right](\mathrm{M})$ 


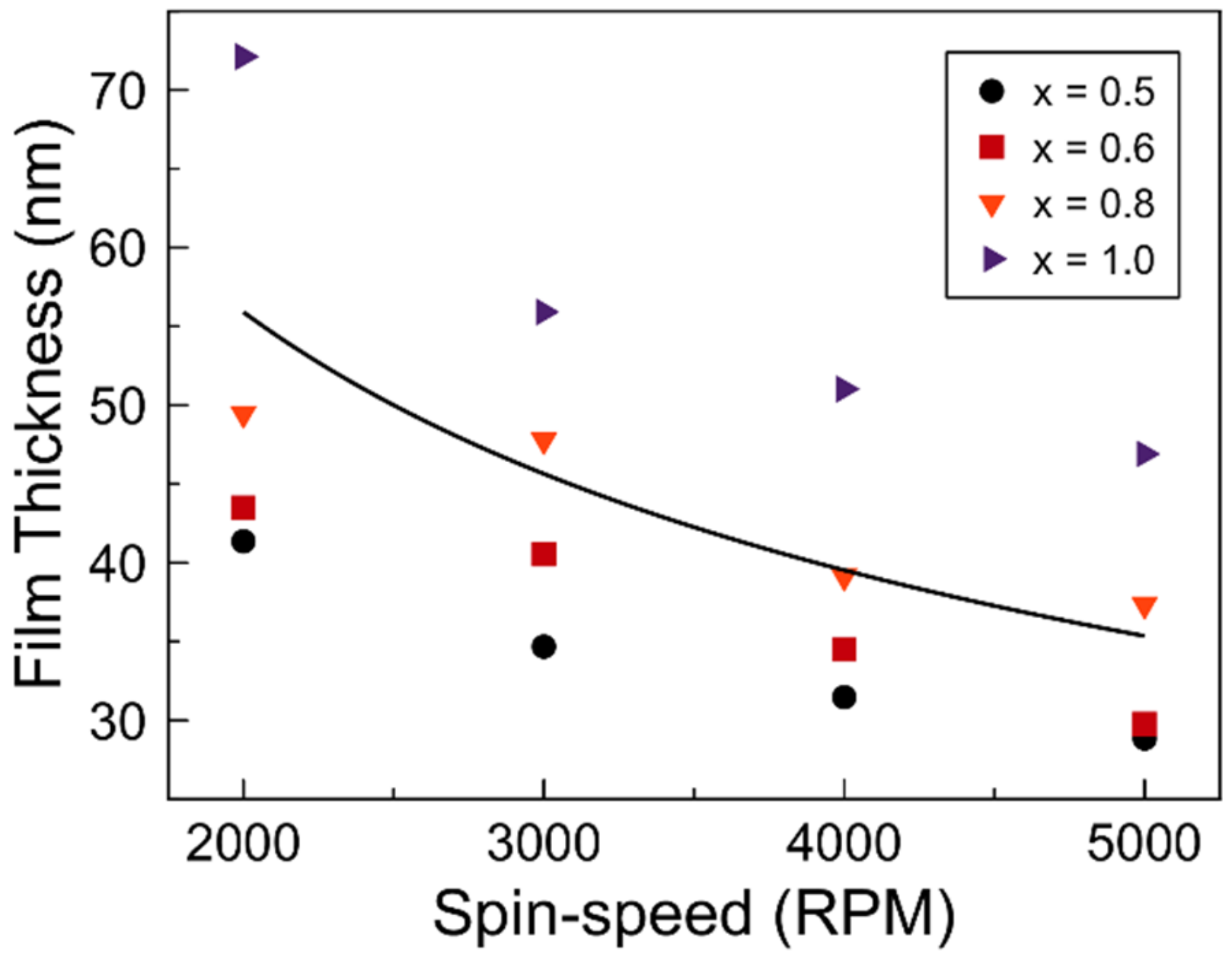




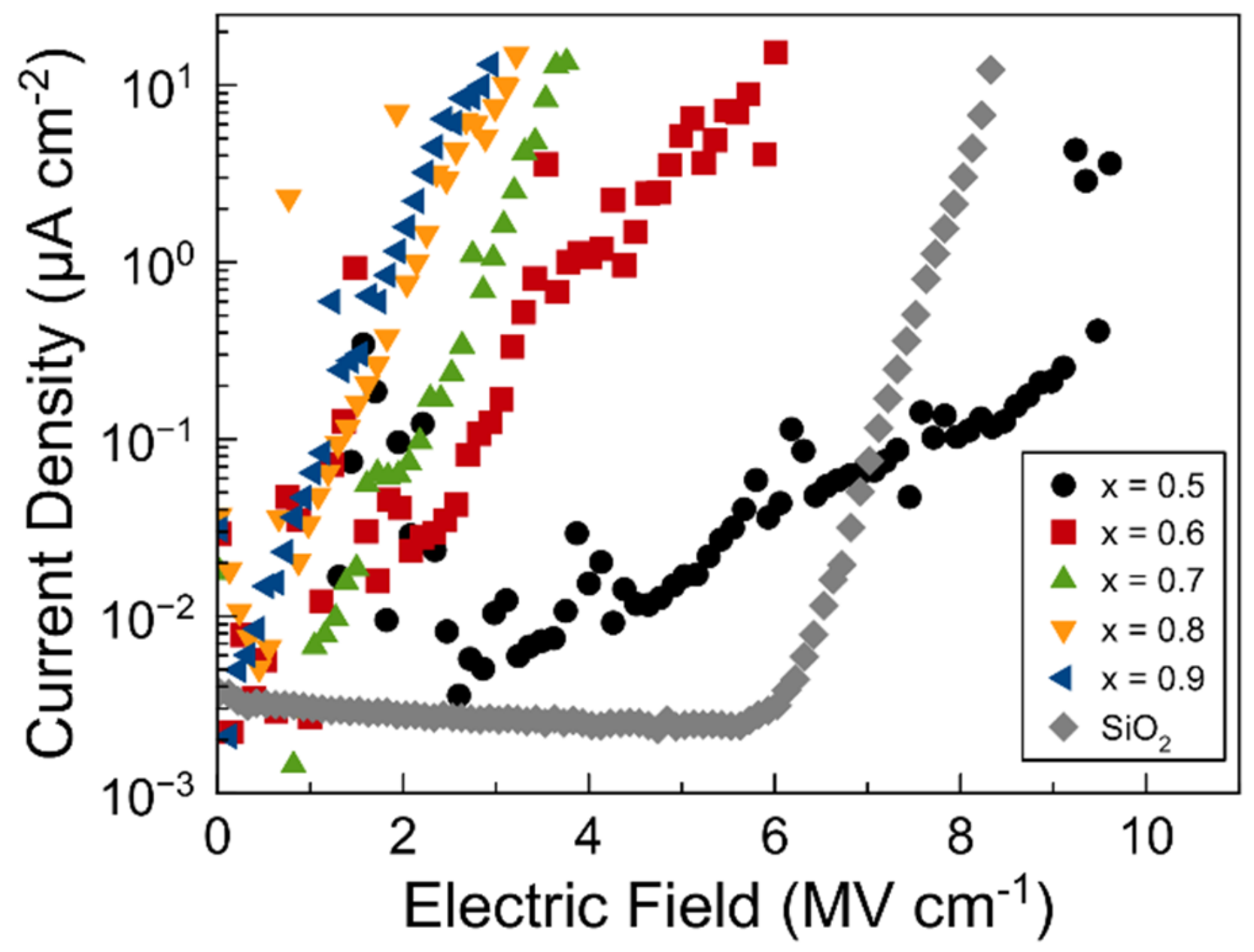




\begin{tabular}{|c|c|}
\hline $\begin{array}{c}\text { Targeted } \mathrm{x} \\
\text { Value }\end{array}$ & $\begin{array}{c}\text { Measured } \\
\text { x Value }\end{array}$ \\
\hline 0.50 & 0.51 \\
\hline 0.60 & 0.62 \\
\hline 0.70 & 0.72 \\
\hline 0.80 & 0.82 \\
\hline 0.90 & 0.94 \\
\hline 1.00 & 1.03 \\
\hline
\end{tabular}




\begin{tabular}{|c|c|c|c|}
\hline $\begin{array}{c}\text { Targeted } \mathrm{x} \\
\text { Value }\end{array}$ & $\begin{array}{c}\text { Film } \\
\text { Thickness } \\
(\mathrm{nm})\end{array}$ & $\begin{array}{c}\text { Mean } \\
\text { Dielectric } \\
\text { Constant }\end{array}$ & $\begin{array}{c}\text { Mean Loss } \\
\text { Tangent (\%) }\end{array}$ \\
\hline 0.50 & 78.3 & 4.7 & 0.5 \\
\hline 0.60 & 83.7 & 4.9 & 1.1 \\
\hline 0.70 & 88.6 & 5.2 & 1.9 \\
\hline 0.80 & 97.4 & 5.9 & 1.1 \\
\hline 0.90 & 99.6 & 5.6 & 1.2 \\
\hline
\end{tabular}


Influence of Composition and Processing Parameters on the Properties of Solution-Processed Aluminum Phosphate Oxide (AIPO) Thin Films

Kevin M. Norelli, Paul N. Plassmeyer, Keenan N. Woods, Benjamin A. Glassy, Christopher C. Knutson, Matt Beekman, and Catherine J. Page

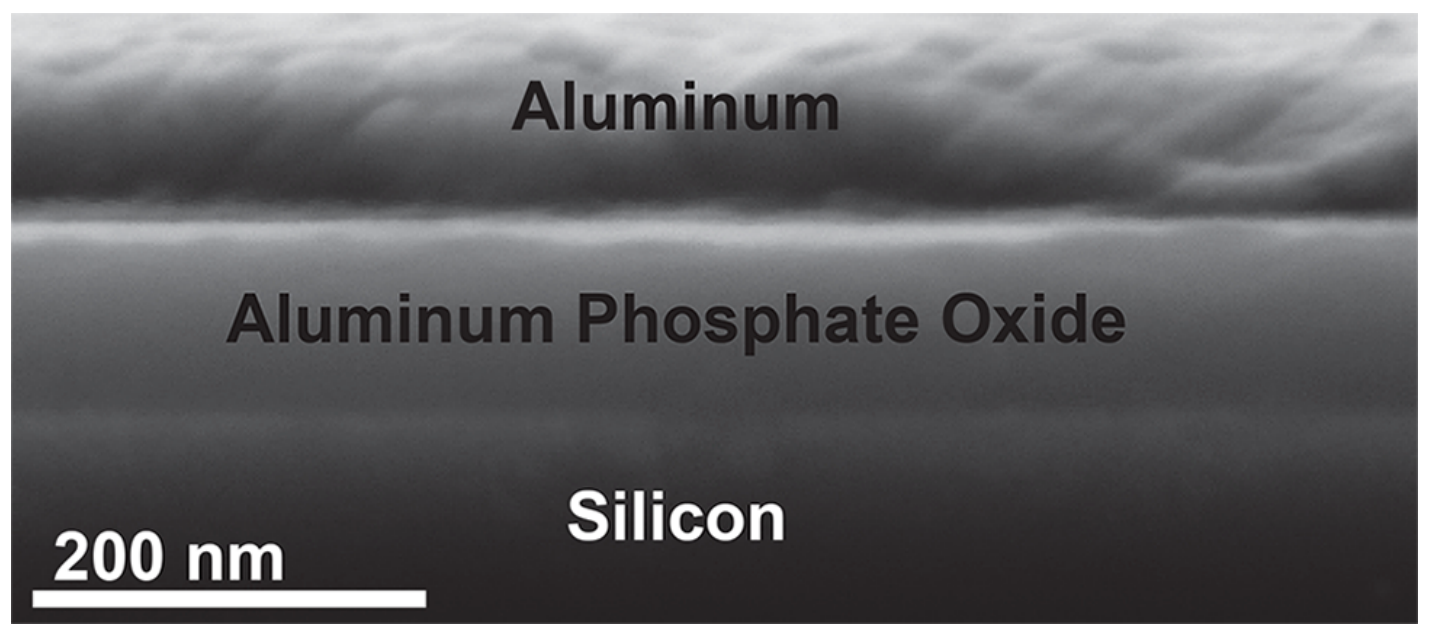

